\title{
SEX- AND AGE-RELATED VARIATION IN SURVIVAL AND COST OF FIRST REPRODUCTION IN GREATER FLAMINGOS
}

\author{
Giacomo Tavecchia, ${ }^{1,2,4}$ Roger Pradel, ${ }^{1}$ Vincent Boy,${ }^{3}$ Alan R. Johnson, ${ }^{3}$ And Frank Cézilly ${ }^{2}$ \\ ${ }^{1}$ CEFE-CNRS, 1919 route de Mende, 34293 Montpellier, Cedex 5, France \\ and ${ }^{2}$ Laborataire d'Ecologie, Université de Bourgogne, Bâtiment Mirande, BP 400, 21011 Dijon Cedex, France \\ ${ }^{3}$ Station Biologique de la Tour du Valat, Le Sambuc 13200 Arles, France
}

\begin{abstract}
We analyzed survival of breeding Greater Flamingos, Phoenicopterus ruber roseus, using the capture histories of 2000 breeding birds ringed as chicks and resighted at their natal colony in the Camargue, southern France. As found in previous analyses, recapture probability varied according to year, sex, and age of the bird, and annual survival was strongly affected by winter severity. However, by using a much larger data set than in earlier analyses, we detected previously nonsignificant effects. Indeed, for the first time, sex and age of the bird were found to influence annual survival probability. We tested the hypothesis that the observed sex-related difference in survival corresponded to asymmetric costs of reproduction. A model including a cost of first observed reproduction on survival in young females only provided the best fit to the data and explained the majority of the sex-related difference in survival of birds $<7 \mathrm{yr}$ old. Because a cost of reproduction may be partially masked by birds that have already bred undetected, we estimated the proportion of experienced females among those observed breeding for the first time. This proportion varied with the age of the birds and was used to calculate the expected cost of early recruitment. Such a cost of early reproduction may have contributed to the evolution of deferred breeding in females. Survival of experienced females was higher than that of males, with the difference being more pronounced in early age classes. Age had a significant positive effect on survival probability of birds.
\end{abstract}

Key words: age-related survival; asymmetric costs; capture-recapture; deferred breeding; Greater Flamingo; Phoenicopterus ruber roseus; reproductive cost; sex-related survival; SURGE.

\section{INTRODUCTION}

Several factors can contribute to differential survival between sexes in vertebrates, including costs of sexually selected traits (Yom-Tov and Ollason 1976, Ligon et al. 1990, Promislow 1992, Promislow et al. 1992) and asymmetrical costs of reproduction (Breitwisch 1989, Michener and Locklear 1990, Clutton-Brock 1991, Pyle et al. 1997). Asymmetric costs are particularly expected in polygamous species in which males and females may exhibit different weighting of the two major components of reproductive effort: effort expended obtaining a mate and effort expended caring for offspring (e.g., Michener and Locklear 1990). Asymmetric costs, however, may also exist in monogamous species, because some of the costs associated with the production of young are paid only by females. Some evidence exists, at least in monogamous bird species, for a sex-biased cost of reproduction in terms of reduced breeding propensity in females (Pugesek and Wood 1992, Pugesek et al. 1995). However, evi-

Manscript received 4 January 1999; revised 9 November 1999; accepted 23 November 1999; final version received 3 January 2000.

${ }^{4}$ Address for Correspondence: Centre d'Ecologie Fonctionelle et Evolutive-CNRS, 1919, route de Mende, 34293 Montpellier Cedex 5, France.

E-mail: tavecchia@cefe.cnrs-mop.fr dence for a sex-biased cost of reproduction in terms of adult survival of monogamous vertebrates remains elusive.

The evaluation of selective pressures that reduce survival, such as a cost of reproduction, requires accurate estimates of adult survival (Clobert 1995, Boulinier et al. 1997), even within manipulative studies (Nur 1988a, 1990). However, in most cases, the evidence for decreased survival caused by high reproductive effort is based on improper survival estimates (Lebreton et al. 1992, Clobert 1995, Viallefont et al. 1995, Boulinier et al. 1997). The best estimates of survival probabilities are obtained from analysis of capture-recapture data with models that estimate survival rate and probability of recapture separately (Lebreton et al. 1993). Progress in methodology over the last 30 years has resulted in an increase in the power of tests and the precision of estimates (Lebreton et al. 1993). These improvements have enabled researchers to provide sound answers to specific biological questions concerning trade-offs between fecundity and survival (Blondel et al. 1992) or age-specific costs of first reproduction (Viallefont et al. 1995). Only a limited number of studies have used such methods for detailed studies of sex-specific patterns of mortality in vertebrates.

A further complication arises in long-lived species in which age may interact with sex in determining the 
observed patterns of sex-related mortality. The large number of age classes under consideration may then impose a limit on the ability to detect small, but still biologically meaningful, effects in capture-recapture models, unless a large enough sample of known-age birds is available (Cochran 1963, Burnham et al. 1987). However, the influence of the interaction between age and sex might be quite important for the study of costs of reproduction, especially if these costs differ between first and subsequent breeding attempts.

Here, we analyze the influence of age and sex on the survival probability of adult Greater Flamingos (Phoenicopterus ruber roseus) breeding in the Camargue (southern France), using sophisticated techniques developed for the analysis of capture-recapture data (Lebreton et al. 1992). The species shows a sexual dimorphism in body mass, with males being, on average, 20\% heavier than females (del Hoyo et al. 1992), suggesting potential competition for food resources, as has been observed in the nominate subspecies, the American Flamingo P. r. ruber (Schmitz and Baldassarre 1992). In addition, some evidence exists that females, particularly young ones, may experience heavy costs during reproduction (Cézilly 1993, Cézilly et al. 1994). Compared to previous attempts (e.g., Cézilly et al. 1996) that failed to model a sex effect on adult survival in this species, the sample size used in the present study is much larger, including 18 age classes studied over 14 consecutive years. We particularly investigate the influence of first observed reproduction on the subsequent survival of males and females.

\section{Materials and Methods \\ Species and study area}

Greater Flamingos are filter feeders that usually breed in dense colonies, often numbering several thousands of pairs. Flamingos have bred in the saline lagoons of the Camargue, southern France, for centuries (Gallet 1949). Since 1974, they have regularly bred on an artificial island situated in a complex of commercial salt pans where water levels are managed for salt production (Johnson 1983, Cézilly et al. 1995), except in 1996, when the birds settled on a nearby island following adverse weather conditions. Since 1977, on average, $12 \%(7-30 \%)$ of the chicks (of unknown sex) reared each year in the Camargue have been marked individually with PVC plastic rings engraved with a three- or four-digit alphanumerical code (Cézilly et al. 1996). Ring codes can be read through a telescope from a distance of up to $400 \mathrm{~m}$. In 1983, a tower hide was built near the breeding island, $70 \mathrm{~m}$ from the closest nests. Every spring throughout the breeding season, this hide is occupied by observers who record the breeding activities of ringed birds. Flamingos were recorded as breeders when they were seen at a nest with an egg or with a chick, or sometimes only much later in the season when they were seen feeding a chick in the crèche. In 1996, observations of breeding birds were performed from a distant dike and using a floating hide.

\section{CMR data analysis}

We analyzed the capture histories of 2000 breeding flamingos (983 females and 1017 males; $\chi_{1}^{2}=0.578, P$ $=0.40$ ) ringed as chicks from 1977 to 1991 and resighted as breeders between 1983 and 1996. This represents about a $50 \%$ increase both in the number of birds involved (2000 instead of 1312) and in the number of resighting years (14 instead of nine) over the most recent survival analysis of the same flamingo population (Cézilly et al. 1996). Because previous analyses of the same population had suggested that survival (Johnson 1983, Lebreton et al. 1992) and recapture probabilities (Cézilly et al. 1996, Pradel et al. 1997) might be age dependent, we considered as a starting point the model $\left(\phi_{t * s * a} ; p_{t * s * a}\right)$ where both survival $(\phi)$ and recapture probabilities $(p)$ are time $(t)$, sex $(s)$, and age $(a)$ dependent (see Lebreton et al. 1992 for model notations). This model is equivalent to the CormackJolly-Seber (CJS) model (which assumes time dependence in both recapture and survival probabilities) applied to each cohort and each sex separately. The ability of model $\left(\phi_{t * s * a} ; p_{t * s * a}\right)$ to describe the data was assessed by repeating for each combination of cohort and sex the goodness-of-fit (GOF) test for the CJS model implemented in program RELEASE (Burnham et al. 1987), and then adding the individual $\chi^{2}$ values and degrees of freedom to build a global test. A significant GOF test might result from one of two causes: structural problems (important effects have been overlooked) or the incorrect assumption that animals behave independently (overdispersion or, more rarely, underdispersion). In the latter case, all variance and deviance values are uniformly inflated. An estimate of the variance inflation factor $\hat{c}$ can be calculated as the ratio of the $\chi^{2}$ value of the global test to its number of degrees of freedom (rdf) (Lebreton et al. 1992). Then, the difference in deviance between nested models no longer follows a $\chi^{2}$ distribution. The traditional likelihood ratio test has to be calculated as an $F$ test:

$$
F_{\Delta \mathrm{df}, \mathrm{rdf}}=(\Delta \mathrm{DEV} / \Delta \mathrm{df}) / \hat{c}
$$

where $\triangle \mathrm{DEV}$ is the change in deviance between the two models and $\Delta \mathrm{df}$ is the related change in degrees of freedom. Hereafter, whenever an $F$ test is used to compare nested models, the probability of a Type I error, if not specified, is from a two-tailed test. Nonnested models can be compared using a modification of the Akaike's (1973) Information Criterion (AIC):

$$
\mathrm{mAIC}=(\mathrm{DEV} / \hat{c})+2 \mathrm{np}
$$

where $n p$ is the number of estimable parameters in the model. The model with the lowest mAIC is the one to be selected. Successive models were built considering factors that are likely to influence survival or recapture 
TABLE 1. Elimination of nonsignificant effects from the model $\left(\phi_{t * a * s} ; p_{t * a * s}\right)$. For each model, we give modified deviance $(\mathrm{mDeviance}=\mathrm{rDEV} / \hat{c})$, number of estimable parameters $(\mathrm{np})$, and modified Akaike's Information Criterion $(\mathrm{mAIC}=[\mathrm{rDEV} / \hat{c}]+2 \mathrm{np})$.

\begin{tabular}{lccc}
\hline \hline Model & mDeviance & $\mathrm{np}$ & $\mathrm{mAIC}$ \\
\hline 1) $\phi_{t * a * s} ; p_{t * a * s}$ & 9708.70 & 430 & 10568.70 \\
2) $\phi_{t * a * s} ; p_{t+a+s}$ & 9851.13 & 258 & 10367.13 \\
3) $\phi_{t * a * s} ; p_{t+A^{2}+s}$ & 9810.77 & 245 & 10300.77 \\
4) $\phi_{t * a * s} ; p_{t+A^{3}+s}$ & 9810.16 & 246 & 10302.16 \\
5) $\phi_{w * a * s} ; p_{t+A^{2}+s}$ & 9969.88 & 81 & 10131.88 \\
6) $\phi_{w * \ln A * s} ; p_{t+A^{2}+s}$ & 9991.76 & 25 & 10041.76 \\
7) $\phi_{w * \ln A * s-w * \ln A . s} ; p_{t+A^{2}+s}$ & 9993.61 & 24 & 10041.61 \\
8) $\phi_{w+\ln A+s+s \cdot \ln A} ; \boldsymbol{p}_{t+A^{2}+s}$ & $\mathbf{9 9 9 8 . 7 8}$ & $\mathbf{2 2}$ & $\mathbf{1 0 ~ 0 4 2 . 7 8}$ \\
\hline
\end{tabular}

Notes: Modified quanties are calculated using an estimate of the variance inflation factor $\hat{c}$

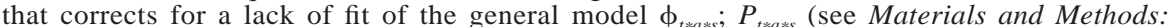
CMR data analysis for calculation of $\hat{c}$ and Lebreton et al. [1992] for model notation). Boldface type denotes the selected model.

probabilities and/or the interactions among them. These models were fitted with program SURGE 4.1 (compiled for UNIX station; Pradel and Lebreton 1991), which yields the deviance of each model up to an unknown constant. This relative deviance (rDEV) suffices for model comparisons. Following the parsimony principle, we compared the various deviances and degrees of freedom in order to identify the model that realized the best compromise in explaining variation in the data while using as few parameters as possible. Indeed, this is what is implemented by the mAIC. However, as a rule of thumb (Lebreton et al. 1992), two models with a difference in their mAIC $<2$ were considered as statistically indistinguishable, and biological considerations took precedence. In this case, the more interpretable or biologically meaningful model was usually retained. For a more detailed description of the general method for selecting models in capture-mark-recapture analysis, we refer the reader to the monograph of Lebreton et al. (1992).

\section{RESUlTS}

\section{Modeling variation of recapture probabilities}

The starting model $\left(\phi_{t * a * s} ; p_{t * a * s}\right)$ was strongly rejected (GOF test: $\left.\chi_{401}^{2}=563.23 ; P=0.000\right)$. Because all component tests were equally affected and no trend could be detected through the contingency tables making up the global test, we calculated $\hat{c}$ an estimate of the variance inflation factor, to correct for lack of fit, and proceeded as indicated in the Materials and methods section (in the present case, $\hat{c}=1.40456$ ).

Eliminating higher order interactions and secondary effects that do not contribute significantly to the deviance improves the precision when estimating survival and recapture probabilities, and consequently increases the power when testing for effects of primary interest (Lebreton et al. 1992). Retracing the steps of Cézilly et al. (1996), we reduced the number of parameters explaining recapture probability in the starting model $\left(\phi_{t * a * s} ; p_{t * a * s}\right)$ by eliminating all interactions between the effects of age, sex, and time simultaneously (Table 1). One way to achieve parsimony is to model smooth, rather than indiscriminate, variations over a factor whenever this is a reasonable consideration. In breeding flamingos, recapture probability is likely to change with age. Indeed, because of the high level of philopatry in successful breeders (Cézilly et al. 1996, Nager et al. 1996, Pradel et al. 1997), it had been found previously that an older bird has a greater chance to be resighted than a younger one. We tried to model the effect of age on the probability of recapture through linear logistic $(A)$, quadratic logistic $\left(A^{2}\right)$, cubic logistic $\left(A^{3}\right)$, and $\operatorname{logarithmic}(\ln A)$ relationships (see Table 1 and the Appendix). The quadratic effect entailed the largest decrease in mAIC and was retained (Table 1). Then, models without the effect of $\operatorname{sex}\left(\phi_{t * a * s} ; p_{t+A^{2}}\right)$ or time $\left(\phi_{t^{*} a * s} ; p_{A^{2}+s}\right)$ or age $\left(\phi_{t_{*} * * s} ; p_{t+s}\right)$ on recapture probability were strongly rejected both by mAIC and by $F$ tests $\left(F_{1,401}=33.47, P=0.000 ; F_{13,401}=15.74, P=\right.$ 0.000 ; and $F_{2,401}=35.00, P=0.000$, respectively). Hence, the probability of resighting in breeding flamingos changed over time, according to the age of the bird (quadratic logistic relationship), and differed between males and females, with females having the lower probability of resighting. From this point, we attempted to simplify the structure of effects on survival (models $5-8$ in Table 1 ).

\section{Modeling factors affecting survival probability}

We next examined survival by successively modeling time as a linear function of an index of winter severity (Hafner et al. 1994) and as a two-level factor, taking into account only the year with the greatest index value (year 1984-1985 vs. all other years together, model $\left(\phi_{w^{*} a * *} ; p_{t+A^{2}+s}\right)$; see also Lebreton et al. 1992). We did the same for age as was done for recapture by testing different functions (linear, quadratic, cubic, and logarithmic). The mAIC pointed to model $\left(\phi_{w * \ln A * s}\right.$; $p_{t+A^{2}+s}$ ) (Table 1). We next tried to eliminate the four interaction terms. The third-order interaction was not significant (model 7 in Table 1). Among the secondorder interactions, only the one between sex and age could not be removed (model $\phi_{w+\ln A+s} ; p_{t+A^{2}+s}$ vs. model 
TABLE 2. Effect of first observed reproduction (1yf) on survival of females $<7 \mathrm{yr}$ old.

\begin{tabular}{|c|c|c|c|}
\hline Model & mDeviance & $\mathrm{np} \dagger$ & $\mathrm{mAIC}$ \\
\hline $8 \phi_{w+\ln A+s+s \cdot \ln A} ; p_{t+A^{2}+s}$ & 9998.78 & 22 & 10042.78 \\
\hline $9 \phi_{w+\ln A+s+1 \mathrm{yf}}^{w+\ln A+s+\ln A}, p_{t+A^{2}+s}^{t+A^{2+s}}$ & 9995.68 & 22 & 10039.68 \\
\hline $10 \phi_{w+\ln A+s+1 \mathrm{yf}+\ln A .1 \mathrm{lyf}} ; p_{t+A^{2}+s}$ & 9991.58 & 23 & 10037.58 \\
\hline $11 \phi_{w+\ln A+s+1 \mathrm{yf}+\ln A .1 \mathrm{yf}+w .1 \mathrm{yf}} ; \boldsymbol{p}_{t+A^{2}+s}$ & 9985.07 & 23 & 10033.07 \\
\hline
\end{tabular}

Notes: The same effect was not found in males or in older females. Calculations of modified deviance (mDeviance), mAIC, and model notation are as in Table 1.

$\dagger$ The number of estimable parameters in each model.

$\left.\phi_{w+\ln A+s+s . \ln A} ; p_{t+A^{2}+s}: F_{1,401}=7.55, P<0.01\right)$. At this stage, however, the mAIC increased slightly.

\section{Cost of early recruitment}

By allowing the survival of birds observed breeding for the first time to differ from that of other birds, we tested for a cost of early recruitment in terms of survival probability. Because first observed breeding is only an approximation to first breeding, we limited the first observed breeding effect to birds $<7 \mathrm{yr}$ old, older birds being much more likely to have bred earlier (Pradel et al. 1997). We did this separately for males and females because it seemed likely that a cost exists mainly in females (Cézilly 1993, Cézilly and Johnson 1995). Under the hypothesis of a trade-off between age of recruitment and survival, the direction of results is clearly predictable (Nur 1988b, Golet et al. 1998). Two-tailed tests must therefore be viewed as unduly conservative, and we used one-tailed tests instead. Cost of early recruitment, tested in this way, was favored for females $\left(F_{1,401}=3.71, P=0.027\right.$; one-tailed test $)$ but rejected for males $\left(F_{1,401}=1.13, P=0.144\right.$; one-tailed test; Table 2 ). In the presence of a cost of early recruitment in

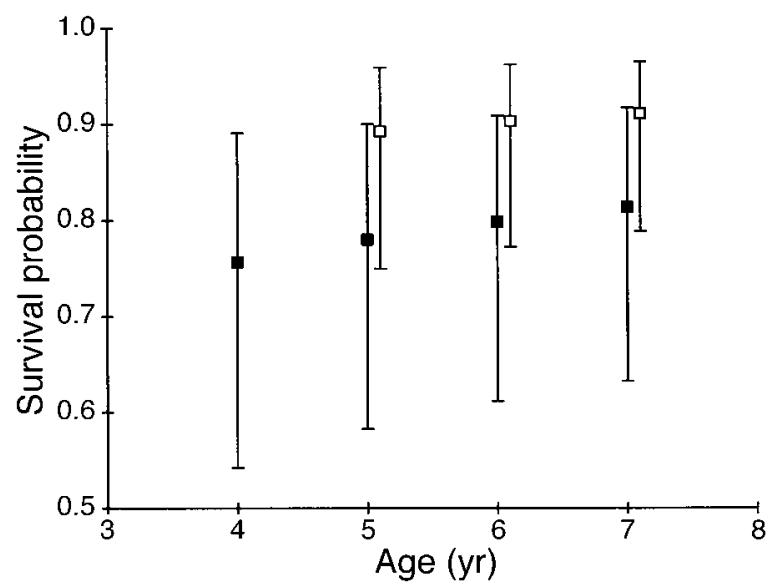

FIG. 1. Pattern of variation in local survival probability of Greater Flamingos with age during 1984-1985; when winter severity caused a great increase in mortality (model $\left(\phi_{w+\ln A+s+1 y f+\ln A .1 y f+w .1 y f} ; p_{t+A^{2}+s}\right)$. In this early year of the study, not all age classes were represented in the breeding population. Males (solid squares) were 4-7 yr old; females (open squares) were 5-7 yr old. Because the small number of individuals at risk in this year, we do not present separate estimates for experienced and naive females. females, the interaction term between sex and age was no longer significant $\left(F_{1,401}=0.61, P=0.6892\right.$; twotailed test). After removing the interaction term, the cost of early recruitment in females (noted as 1yf) became unequivocally significant $\left(\phi_{w+\ln A+s+1 \mathrm{yf}} ; p_{t+A^{2}+s}\right.$ vs. $\phi_{w+\ln A+s}$; $p_{t+A^{2}+s} ; F_{1,401}=10.65, P=0.001$; two-tailed). We tested two effects: (1) whether the cost of first reproduction changes with age (first-order interaction, denoted age.1yf in model 10); and (2) whether, given a particular age, the cost of first reproduction was greater during the harsh winter of 1985 (denoted $w .1 \mathrm{yf}$ in model 11). We introduced the two interaction effects in two different models (10 and 11, in Table 2 and Fig. 1). Both interaction terms were significant. Further attempts to improve the model $\left(\phi_{w+\ln A+s+1 \mathrm{yf}+\ln A .1 \mathrm{yf}+w .1 \mathrm{yf}} ; p_{t+A^{2}+s}\right)$ failed (Table 3 ). We finally checked whether age variations in the survival of males and experienced females were still significant by examining the equation coefficient of the retained model. If the age-related coefficient was not significantly different from zero, then survival was considered constant. We favored this approach, instead of building a new model, because the main age effect could not be removed, as its interaction with the first-year effect in females was significant. Also, survival covaried significantly with age when the survival of young females was modeled according to their breeding experience $(z=1.76, P=0.039)$; see Figs. 2 and 3 .

The proportion of experienced birds among those seen breeding for the first time, $x$, can be calculated as $1-\gamma / \xi$ (R. Pradel, unpublished data), where $\xi$ is the probability of being seen breeding for the first time,

TABle 3. Test of winter, age, sex, female, and male first reproduction effects on survival.

\begin{tabular}{lcc}
\hline \hline \multicolumn{1}{c}{ Effect } & $F_{1,401}$ & $P$ \\
\hline$+w . \ln A .1 \mathrm{yf}$ & 0.007 & 0.933 \\
$+\ln A . s$ & 0.028 & 0.867 \\
$+1 \mathrm{ym}$ & 0.036 & 0.850 \\
+ w. $\ln A$ & 0.057 & 0.812 \\
+ w.s & 0.377 & 0.539 \\
$-\ln A .1 \mathrm{yf}$ & 6.166 & 0.013 \\
$-w .1 \mathrm{yf}$ & 6.514 & 0.011 \\
$-\mathrm{s}$ & 10.145 & 0.001
\end{tabular}

Notes: The effect considered is removed ( - ) (if present) or added $(+)$ (if absent) to the previously selected model $\left(\phi_{w+\ln A+A+s+\operatorname{lyf}+\ln A . \operatorname{lyf}+w .1 \mathrm{yf}} ; p_{t+A^{2}+s}\right)$. Then, an $F$ test is computed based on the resulting change in deviance and the variance inflation factor (see Materials and methods for details). 


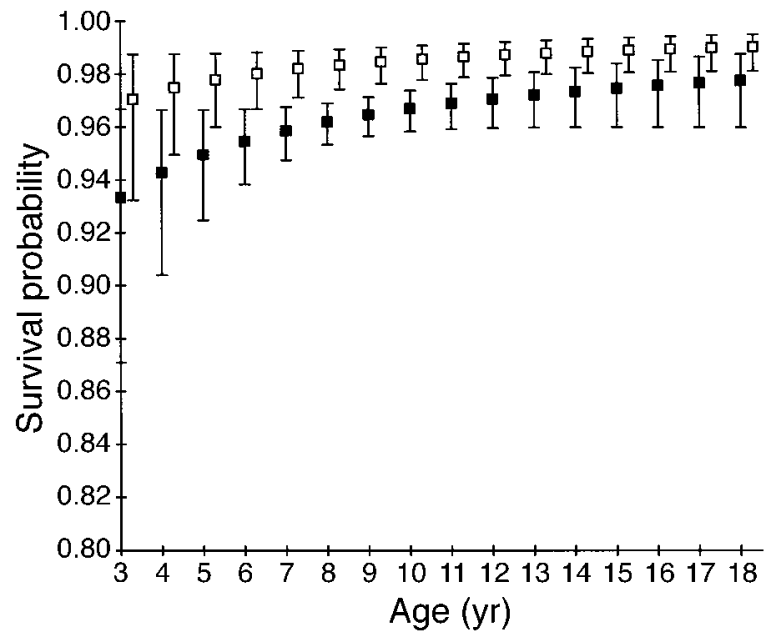

FIG. 2. Pattern of variation in local survival probability of Greater Flamingos with age, using model $\left(\phi_{w+\ln A+s+1 y f+\ln A .1 \mathrm{yf}+w .1 \mathrm{yf} ;}\right.$; $\left.p_{t^{+} A^{2}+s}\right)$. Survival probability of first breeders, females $<7 \mathrm{yr}$ old, are not plotted. Plotted values are from "normal" years (no cold spell). Solid squares represent males; open squares represent females.

and $\gamma$ is the seniority probability (Pradel et al. 1997; see also Pradel 1996), i.e., the probability that an animal has bred at least once earlier (independently of its being seen). Estimates of these quantities for 11 cohorts (from 1977 to 1988) are available from a previous study of local recruitment of the same population (Pradel et al. 1997). We used these estimates to calculate the expected numbers of experienced flamingos among those seen breeding for the first time at the different ages (Table 4). Considering as a first approximation that the survival estimate of first-observed breeding females $\phi_{\mathrm{n}}$ as given by the final model $\left(\phi_{w+\ln A+s+1 \mathrm{yf}+\ln A .1 \mathrm{yf}+w .1 \mathrm{yf}} ; p_{t+A^{2}+s}\right)$ is a weighted average of the true survival of naive females $\phi_{n}^{*}$ and of the survival of experienced females, of which an estimate $\phi_{\mathrm{e}}$ is also given by model $\left(\phi_{w+\ln A+s+1 \mathrm{yf}+\ln A .1 \mathrm{yf}+w .1 \mathrm{yf}} ; p_{t+A^{2}+s}\right)$, we estimated $\phi_{\mathrm{n}}^{*}$ as

$$
\phi_{\mathrm{n}}^{*}=\left(\phi_{\mathrm{n}}-x \phi_{\mathrm{e}}\right) /(1-x) .
$$

Through all three age classes for which we could calculate $\phi_{\mathrm{n}}^{*}$, the cost in survival for females breeding for the first time decreased sharply with age from 0.19 at age 4 yr to nearly 0 at age 6 yr (Table 4 ). We also sought a cost of early recruitment in a reduced probability of breeding in the year following the first breeding attempt. Such a cost would show as a lower recapture probability in that year (Viallefont et al. 1995). Again using the approximation of first observed breeding, we could not detect such an effect $\left(\phi_{w+\ln A+s+1 \mathrm{yf}+\ln A .1 \mathrm{lyf}+w .1 \mathrm{yf}} ; p_{t+A^{2}+s+1 \mathrm{yf}} \mathrm{Vs}\right.$. $\phi_{w+\ln A+s+1 \mathrm{yf}+\ln A .1 \mathrm{yf}+w .1 \mathrm{yf}} ; p_{t+A^{2}+s}: F_{1,401}=0.14, P=0.354$; one-tailed test). Thus, only the survival of females $<7$ yr old seemed to be affected by early recruitment.

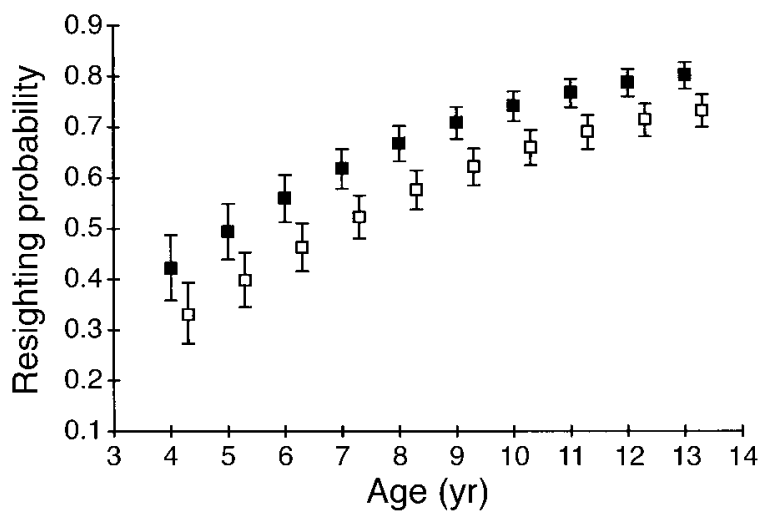

FIG. 3. Sex-and age-dependent values of resighting probability for the birds present in 1991, as estimated by the model $\phi_{w+\ln A+s+1 \mathrm{yf}+\ln A .1 \mathrm{lyf}+w .1 \mathrm{lyf}} ; p_{t+A^{2}+s}$. Solid squares represent males; open squares represent females.

\section{DISCUSSION}

\section{Age effect on survival}

With the exception of females $<7$ yr old breeding for the first time, the estimates of survival were high (above 0.93 and 0.97, respectively, for males and experienced females in a normal year), and lay well outside the $95 \%$ confidence interval of the previous estimate based upon the assumption of constant survival across sex and age (Cézilly et al. 1996). Age had a globally significant, positive influence on survival in breeding birds. A slight increase in the survival of breeding adults over the first age classes has also been found in the long-lived and colonial Great Cormorant (Phalococorax carbo), using an extensive resightings and recoveries data set (Frederiksen and Bregnballe 2000). Forslund and Pärt (1995) have reviewed several hypotheses that can explain an increase in reproductive performance with age; at least two of them could also hold for an increase in survival probability. If natural selection progressively eliminates low-quality phenotypes, the proportion of high-quality individuals should increase through age classes and, consequently, sur-

TABLE 4. Effect of first reproduction on female flamingos $<7$ yr old.

\begin{tabular}{|c|c|c|c|c|}
\hline \multirow[b]{2}{*}{ Terms $\dagger$} & \multicolumn{4}{|c|}{ Age (yr) } \\
\hline & 3 & 4 & 5 & 6 \\
\hline$x$ & $0.006(6)$ & $0.10(38)$ & $0.21(95)$ & $0.41(125)$ \\
\hline$\phi_{\mathrm{e}}$ & & 0.975 & 0.978 & 0.980 \\
\hline$\phi_{\mathrm{n}}$ & 0.408 & 0.768 & 0.926 & 0.979 \\
\hline$\Delta \phi$ & & 0.186 & 0.041 & 0.001 \\
\hline
\end{tabular}

$\dagger$ Definitions are as follows: $x$ is the expected proportion of experienced females among first-observed-breeding females (sample size in parentheses) estimated from 11 cohorts from 1977 to 1988 (data from Pradel et al. [1997]; $\phi_{\mathrm{e}}$ is the survival of experienced females; $\phi_{n}$ is the survival probability of first-observed-breeding females estimated from model $\phi_{w+\ln A+s+1 \mathrm{yf}+\ln A .1 \mathrm{yf}+w .1 \mathrm{yf}} ; p_{t+A^{2}+s} ;$ and $\phi_{\mathrm{n}}{ }^{*}$ is the expected survival of naive females estimated as $\left(\phi_{\mathrm{n}}-x \phi_{\mathrm{e}}\right) /(1-x)$. 
vival should covary positively with age ("selection hypothesis" in Forslund and Pärt). Alternatively, agedependent survival could result from an age-related improvement in competence (Pyle et al. 1991). According to Forslund and Pärt (1995), who have reviewed the evidence supporting those hypotheses, results are contradictory. In the Greater Flamingo, specific selective pressures seem to act on breeding females in early age classes, supporting the idea that at least the selection hypothesis may hold for this category (see also General conclusion). However, the two explanations just presented are not mutually exclusive. We did not find any evidence of senescence, as has been observed in some other bird species (Coulson and Wooller 1976, Ainley and DeMaster 1980, Aebischer and Coulson 1990, Pugesek and Diem 1990, Wooller et al. 1992, Newton and Rothery 1997, Frederiksen and Bregnballe 2000). However, the maximum age in our data set was only $18 \mathrm{yr}$, whereas recorded maximum longevity of Greater Flamingos is $40 \mathrm{yr}$ in the wild (A. R. Johnson, unpublished data) and $>60 \mathrm{yr}$ in captivity (A. Studer-Thiersch, personal communication). Presumably, if senescence does occur in the Greater Flamingo, it should begin later in life (at least after 18 yr). In this scenario, with senescence being so remote in age, the life expectancy of the youngest flamingos increases during their first years, as they start by having a relatively low annual probability of survival. Therefore, if investment in reproduction were under the sole control of restraint (Curio 1983), and assuming that reproductive success is directly correlated with reproductive investment (Forslund and Pärt, 1995), young individuals should invest more, and thus have a higher reproductive success, than older birds. The contrary is observed (F. Cézilly and R. Nager, unpublished data). Thus, some constraints must act in younger ages to limit reproduction (constraint hypothesis), either individually or on the average, if individuals of poor quality, later eliminated by natural selection, are still present.

\section{Sex-related variation in survival}

In birds and mammals, there is evidence that differences in male and female mortality are correlated positively with size dimorphism (Searcy and Yasukawa 1981, Promislow 1992, Promislow et al. 1992, OwenSmith 1993). A slight size dimorphism exists between male and female Greater Flamingos, with females being $20 \%$ lighter than males, on average (del Hoyo et al. 1992). Yom-Tov and Ollason (1976) proposed that intersexual size dimorphism and competition for access to resources were directly responsible for the observed patterns of sex-biased mortality in birds. Size difference between males and females has been observed to be the principal determinant of outcomes during aggressive encounters over food in the closely related American Flamingo Phoenicopterus. r. ruber (Schmitz and Baldassare 1992). However, if the "competition hypothesis" can explain why young first-breeding females survive less than males, it cannot account for the higher survival of experienced females as compared to males. A similar male-biased mortality among breeding adults has been found in the Kittiwake (Rissa tridactyla), in which males are slightly heavier than females (Aebisher and Coulson 1990). Another fact that contradicts the competition hypothesis concerns periods of particularly high mortality. At this time, competition is supposed to become more evident. Ward (1965) has provided some support for this conclusion by showing that female Zebra Finches (Quelea quelea) are at a greater disadvantage than males in periods of food shortages. If this were indeed the case for flamingos, one would expect the consequences of intersexual competition to be more severe when populations are facing harsh conditions, especially when food availability becomes limited. Such a situation occurred in the Camargue during the winter of 1984-1985, when lagoons remained frozen for 2-3 weeks, causing the death of $\sim 6000$ flamingos wintering in southern France (Johnson et al. 1991). In our analysis, however, there was no significant interaction between sex and winter severity on survival and, except when compared to young females breeding for the first time, males always had a higher mortality than females.

Overall, our results suggest that the observed sexrelated difference in survival in this species does not result from a competition between the two sexes for access to food resources. It seems to us very unlikely that there exists a single selective pressure able to account for both sex-biased mortality and size dimorphism. Both characters are likely under specific intrasexual, rather than intersexual, selective forces. Indeed, it is possible that specific selective pressures are at work among the younger female age classes, acting as a filter for high-quality breeders. According to this hypothesis, which is supported by the finding of a low survival of first-breeding young females, but not of first-breeding young males, the proportion of low-quality individuals would remain higher among males than among experienced females. This, in turn, would result in the observed higher mean mortality of males, regardless of the age of the birds or the environmental conditions. An alternative explanation for the observed pattern of mortality could be that experienced females are more site faithful than are males, resulting in sexrelated differences in permanent emigration and, hence, sex-related difference in estimates of local survival. However, previous detailed studies of the same population (Nager et al. 1996) have found no sex effect on breeding dispersal.

\section{Sex-related cost of first reproduction}

Trivers (1972) has suggested that, in monogamous species, females expend higher levels of parental investment than males. Although male and female flamingos equally share incubation and chick-raising du- 
ties (Cézilly 1993), only females support the cost of egg production and egg laying. Indeed, egg production can be energetically expensive (see Monaghan and Nager 1997, Monaghan et al. 1998), particularly in nonpasserine species hatching precocial young (Ricklefs 1974). Previous studies (Cézilly 1993, Cézilly et al. 1994) have provided evidence that female flamingos, especially younger ones, may be energetically limited. In the present analysis, controlling for interannual variation in environmental conditions (winter severity) and for the increase in survival with age, we found that first reproduction incurred a heavy cost in reduced survival in females $<7 \mathrm{yr}$ old, but not in males. This result is surprising, considering the extensive literature outlining the difficulty of demonstrating a reproductive trade-off using correlative data. The argument that individuals adjust their reproductive effort to their intrinsic quality implies that low-quality individuals should invest less, with no apparent cost of first reproduction (Williams 1966, van Noordwijk et al. 1981, Reznick 1985, Nur 1988a, Partridge and Harvey 1988, Lindén and Møller 1989, Wiemerskirch 1992; but see Ekman and Askenmo 1986, Viallefont et al. 1995, Pyle et al. 1997). However, the hypothesis that high-quality individuals have higher survival and reproduce early in life does not provide sufficient explanation for our results. For instance, if most females that breed early (e.g., when $<7$ yr old) are essentially high-quality individuals, we would not expect the huge difference in survival between experienced and naive female breeders (because low-quality females would not breed) that we found in the younger age classes (Table 4). Moreover, the increasing presence, with age, of low-quality females among breeders should tend to a decrease in average survival with age, not to the increase that we found. As surprising as our results may be, they are not unique. An age-related cost of first reproduction has also been found by Pyle et al. (1997) in a correlative study on the Western Gull (Larus occidentalis). In this species, reproduction is deferred until age $4 \mathrm{yr}$ for males and ages 5-7 yr for females, and young, inexperienced Western Gulls suffer higher mortality than do older birds. The authors have concluded that deferred breeding may have evolved in response to an age-related cost of reproduction (Pyle et al. 1997). Actually, there is evidence that flamingos breeding in the Camargue delay first reproduction beyond the age at which they are physiologically mature. Indeed, most females recruit between 5 and 6 yr old, whereas sexual maturity is reached at age $3 \mathrm{yr}$. It is more difficult to understand why males, which unlike females do not suffer from higher mortality when first breeding at 3 or $4 \mathrm{yr}$ old, nonetheless share the same pattern of recruitment (Pradel et al. 1997). Age of first breeding in males may be shaped by different selective pressures. For instance, it is possible that access to reproduction is costly for young males but not for females, whereas first reproduction in itself is more costly for young females but not for males. A differential cost of reproductive effort has been demonstrated for other vertebrates such as Richardson's ground squirrel, in which mating period is costly for males but not for females, and reproduction appears to be costly for females but not for males (Michener and Locklear 1990). Another possibility is that delayed recruitment of young males is the direct consequence of the female pairing preference for older males, as suggested by observed patterns of age-assortative pairing in the Camargue population (see Cézilly et al. 1997).

\section{Resighting probability}

The probability of resighting varies significantly with time, sex, and age of the birds, confirming previous findings for the same population (Cézilly et al. 1996, Pradel et al. 1997). Variation over time in resighting probability is likely to reflect changes in effort or population size (Viallefont et al. 1995, Cézilly et al. 1996). In contrast, sex or age variations may be biologically informative because they could reflect breeding frequency. For instance, Pugesek et al. (1995) have concluded that a lower resighting probability of female California Gulls (Larus californicus) is due to a higher frequency of females that skip breeding. For the same reason, they have concluded that young gulls appear to skip reproduction more often than do adults. Similarly, Viallefont et al. (1995) have found in Lesser Snow Geese (Anser caerulescens cearulescens) that young first breeders tend to skip the subsequent reproduction. If the hypothesis that resighting probability reflects breeding frequency holds for the Greater Flamingo, our results would suggest that young birds skip reproduction more often than do adults, and females skip more often than old males. Thus, young females would skip reproduction more than do any other birds. Although it is very likely that reproductive skipping exists in a long-lived species such as the Greater Flamingo, we tested but did not retain the specific hypothesis that young females breeding for the first time tend to skip the subsequent reproduction. In flamingos, variations of resighting rate with age may reflect a progressive access to regular reproduction, but the sex effect could also be due to a difference between males and females in their probability of renesting after a breeding failure (Cézilly 1993, Cézilly and Johnson 1995, Pradel et al. 1997).

\section{General conclusion}

Survival of Camargue flamingos has been previously estimated from recoveries of birds ringed as chicks (Johnson 1983) or from resightings (Johnson et al. 1991, Lebreton et al. 1992, Cézilly et al. 1996). Wintering areas (Johnson et al. 1991), age, and winter severity (Lebreton et al. 1992) had been found to affect adult survival, but no sex effect on survival had been reported (Johnson 1983, Johnson et al. 1991, Lebreton et al. 1992, Cézilly et al. 1996). In contrast, our analysis 
provides clear evidence for a difference in survival between male and female breeding flamingos. Because the present study is based on a much larger data set, this confirms that the power of capture-recapture models to detect significant biological effects will vary with sample size (Cochran 1963, Burnham et al. 1987). This also emphasizes the need to design capture-recapture studies carefully in terms of effort according to the questions of interest. The consequences of an increased number of individuals and years of recapture in modeling survival and recapture probabilities are not clearly distinguishable. However, the evidence of a slight difference in survival between males and females is probably due more to an increased number of individuals in the data set, whereas adding years of resighting increases the probability of detecting age-dependent effects.

According to our results, first reproduction in young females is by far the strongest factor in mortality among adult flamingos. First reproduction may thus act as a filter selecting females of intrinsically high quality (Coulson and Porter 1985), resulting in an increased survival of females relative to males in older age classes. This hypothesis seems to be in agreement with most of our findings concerning the pattern of age and sex variation of survival. First, the increase in survival with age in female flamingos would correspond to a progressive disappearance of phenotypes of lesser quality ("selection hypothesis;" Forslund and Pärt 1995). Second, assuming that naive males and females are, on average, of approximately the same quality, the hypothesis predicts that experienced females will show an enhanced survival as compared to males, whereas naive females breeding for the first time should have a lower survival. This is indeed what we observed. However, why does first reproduction not act as a filter to select higher quality males, which nonetheless appear to delay reproduction just like females? The hypothesis that low-quality individuals are constrained or prevented from breeding early may hold for males because we did not find any evidence of an increased mortality in males breeding for the first time before age 7 yr. Alternatively, it is possible that selection for high-quality males occurs in the immature ages (i.e., during first winter or migration), which we are not able to investigate with the current data set.

A body of facts is thus congruent with the idea that cost of first reproduction, which appears to be quantitatively considerable among breeding female flamingos, and harsh winter conditions are the major determinant of the species' dynamics. This idea could be further tested if we had indications about the sex ratio in the population as a whole at different ages, and if we had some knowledge of sex-specific juvenile (prebreeding) survival.

\section{ACKNOWLEDGMENTS}

It is impossible to list all of the assistants who contributed by their observations of over 6000 resightings of marked birds at the Camargue colony used here, but this study was largely made possible by their work and by permission from the salt company to study on their property. Many thanks also to $\mathrm{M}$ Lambrechts, Vladimir Grosbois, and Elizabeth Brooks for their important comments and suggestions on an early draft of the manuscript. We are very grateful to N. Nur and an anonymous referee for final comments on both data analysis and discussion. G. Tavecchia was supported by a grant from the Università degli Studi di Pavia and a fellowship from the French Government.

\section{Literature Cited}

Aebischer, N. J., and J. C. Coulson. 1990. Survival of Kittiwakes in relation to sex and position in colony. Journal of Animal Ecology 59:163-171.

Ainley, D. G., and D. P. DeMaster. 1980. Survival and mortality in a population of Adélie Penguins. Ecology 61:522530.

Akaike, H. 1973. Information theory and an extension of the maximum likelihood principle. Pages 267-281 in B. N. Petran and F. Csàki, editors. International Symposium on Information Theory. Second edition. Akadémiai Kiadi, Budapest, Hungary.

Blondel, J., R. Pradel, and J.-D. Lebreton. 1992. Low fecundity insular blue tits do not survive better as adults than high fecundity mainland ones. Journal of Animal Ecology 61:205-213.

Boulinier, T., G. Sorci, J. Clobert, and E. Danchin. 1997. An experimental study of the cost of reproduction in the Kittiwake Rissa tridactyla: comment. Ecology 78:1284-1287.

Breitwisch, R. 1989. Mortality patterns, sex ratios, and parental investment in monogamous birds. Pages 1-50 in D. M. Power, editor. Current Ornithology. Volume 6. Academic Press, New York, New York, USA.

Burnham, K. P., D. R. Anderson, G. C. White, C. Brownie, and K. H. Pollock. 1987. Design and analysis methods for fish survival experiments based on release-recapture. American Fisheries Society Monograph 5.

Cézilly, F. 1993. Nest desertion in the Greater Flamingo, Phoenicopterus ruber roseus. Animal Behaviour 45:10381040.

Cézilly, F., V. Boy, R. E. Green, G. J. M. Hirons, and A. R. Johnson. 1995. Interannual variation in Greater Flamingo breeding success in relation to water levels. Ecology 76: 20-26.

Cézilly, F., V. Boy, C. J. Tourenq, and A. R. Johnson. 1997. Age-assortative mating in the Greater Flamingo Phoenicopterus ruber roseus. Ibis 139:331-336.

Cézilly, F., and A. R. Johnson. 1995. Re-mating between and within breeding seasons in the Greater Flamingo Phoenicopterus ruber roseus. Ibis 137:543-546.

Cézilly, F., C. J. Tourenq, and A. R. Johnson. 1994. Variation in parental care with offspring age in the Greater Flamingo. Condor 96:809-812.

Cézilly, F., A. Viallefont, V. Boy, and A. R. Johnson. 1996. Annual variation in survival and breeding probability in Greater Flamingos. Ecology 77:1143-1150.

Clobert 1995. Capture-recapture and evolutionary biology: a difficult wedding. Journal of Applied Statistics 22:9891008.

Clutton T. H. 1991. The evolution of parental care. Princeton University Press, Princeton, New Jersey, USA.

Cochran, W. G. 1963. Sampling techniques. John Wiley, New York, New York, USA.

Coulson, J. C., and R. D. Wooller. 1976. Differential survival rates among breeding Kittiwake gulls Rissa trydactyla. Journal of Animal Ecology 45:205-213.

Coulson, J. C., and J. M. Porter. 1985. Reproductive success of the Kittiwake (Rissa tridactyla): the roles of clutch size, chick growth rates and parental quality. Ibis 127:450-466. 
Curio, E. 1983. Why do young birds reproduce less well? Ibis 125:400-404.

del Hoyo, J., A. Elliott, and J. Sargatal. 1992. Handbook of the birds of the world. Volume 1. Lynx Edicions, Barcelona, Spain.

Ekman, J., and C. Askenmo. 1986. Reproductive cost, agespecific survival and comparison of the reproductive strategy in two European tits (genus Parus). Evolution 40:159168.

Forslund, P., and T. Pärt. 1995. Age and reproduction in birds-hypothesis and tests. Trends in Ecology and Evolution 10:374-378.

Frederiksen, M., and T. Bregnballe. 2000. Evidence for density-dependent survival in adult cormorants from a combined analysis of recoveries and resightings. Journal of Animal Ecology 69, in press.

Gallet, E. 1949. Les Flamants roses de Camargue. Payot, Lausanne, France.

Golet, G. H., D. B. Hirons, and J. A. Estes. 1998. Survival cost of chick rearing in Black-legged Kittiwakes. Journal of Animal Ecology 67:827-841.

Hafner, H., O. Pineau, and Y. Kayser. 1994. Ecological determinants of annual fluctuations in numbers of breeding Little Egrets (Egretta garzetta L.) in the Camargue, S. France. Revue d'Ecologie (Terre et Vie) 49:53-62.

Johnson, A. R. 1983. Etho-Ecologie du Flamant rose (Phoenicopterus ruber roseus, Pallas) en Camargue et dans l'Ouest paléarctique. Université Paul Sabatier,Toulouse, France.

Johnson, A. R., R. E. Green, and G. J. M. Hirons. 1991. Survival rates of Greater Flamingos in the west Mediterranean region. Pages 249-271 in C. M. Perrins, J.-D. Lebreton, and G. J. M. Hirons, editors. Bird population studies. Oxford University Press, Oxford, UK.

Lebreton, J. D., K. P. Burnham, J. Clobert, and D. R. Anderson. 1992. Modeling survival and testing biological hypotheses using marked animals: a unified approach with case studies. Ecological Monographs 61:67-118.

Lebreton, J.-D., R. Pradel, and J. Clobert. 1993. The statistical analysis of survival in animal populations. Trends in Ecology and Evolution 8:91-95.

Ligon, J. D., R. Thornhill, M. Zuk, and K. Johnson. 1990. Male-male competition, ornementation and the role of testosterone in sexual selection in red jungle fowl. Animal Behaviour 40:367-373.

Lindén, M., and A. P. Møller. 1989. Cost of reproduction and covariation of life history traits in birds. Trends in Ecology and Evolution 4:367-371.

Michener, G. R., and L. Locklear. 1990. Differential costs of reproductive effort for male and female Richardson's ground squirrels. Ecology 71:855-868.

Monaghan, P., and R. G. Nager. 1997. Why don't birds lay more eggs? Trends in Ecology and Evolution 12:270-274.

Monaghan, P., R. G. Nager, and D. C. Houston. 1998. The price of eggs: increased investment in egg production reduces the offspring rearing capacity of parents. Proceedings of the Royal Society of London. Series B 265:1731-1735.

Nager, R. G., A. R. Johnson, V. Boy, M. Rendon-Martos, J. Calderon, and F. Cézilly. 1996. Temporal variation in dispersal in the Greater Flamingo (Phoenicopterus ruber roseus). Oecologia 107:204-211.

Newton, I., and P. Rothery. 1997. Senescence and reproductive value in Sparrowhawks. Ecology 78:1000-1008.

Nur, N. 1988a. The cost of reproduction in birds: an examination of the evidence. Ardea 76:155-168.

Nur, N. 1988b. The consequences of brood size for breeding blue tits. III. Measuring the cost of reproduction: survival, future fecundity, and diffrential dispersal. Evolution 42 : $351-362$.

Nur, N. 1990. The cost of reproduction in birds: evluating the evidence from manipulative and non-manipulative stud- ies. Pages 281-296 in J. Blondel, A. Gosler, J.-D. Lebreton, and R. McCleery, editors. Population biology of passerine birds: an integrated approach. NATO ASI Series G: Ecological Sciences. Volume 24. Springer-Verlag, Berlin, Germany.

Owen-Smith, N. 1993. Comparative mortality rates of male and female kudus: the costs of sexual size dimorphism. Journal of Animal Ecology 62:428-440.

Partridge, L., and P. H. Harvey. 1988. The ecological context of life history evolution. Science 241:1449-1454.

Pradel, R. 1996. Utilization of capture-mark-recapture for the study of recruitment and population growth rate. Biometrics 52:703-709.

Pradel, R., A. R. Johnson, A. Viallefont, R. G. Nager, and F. Cézilly. 1997. Local recruitment in the Greater Flamingo: a new approach using capture-mark-recapture data. Ecology 78:1431-1445.

Pradel, R., and J.-D. Lebreton. 1991. User's manual for program SURGE version 4.1, CEFE/CNRS, BP 5051, Doc. 17. CEFE-CNRS-M19, route de Mende 34293, Montpallier, Cedex 5, France 〈ftp.cefe.cnrs-mop.fr plus directory /pub/ biom/Surge).

Promislow, D. E. L. 1992. Costs of sexual selection in natural populations of mammals. Proceedings of the Royal Society of London, Series B 247:203-210.

Promislow, D. E. L., R. Montgomerie, and T. E. Martin. 1992. Mortality costs of sexual dimorphism in birds. Proceedings of the Royal Society of London, Series B 250:143-150.

Pugesek, B. H., and K. L. Diem. 1990. The relationship between reproduction and survival in known-aged California Gulls. Ecology 71:811-817.

Pugesek, B. H., C. Nations, K. L. Diem, and R. Pradel. 1995. Mark-resighting analysis of California Gull population. Journal of Applied Statistics 22:625-639.

Pugesek, B. H., and P. Wood. 1992. Alternative reproductive strategies in the California Gull. Evolutionary Ecology 6: 279-295.

Pyle, P., N. Nur, W. J. Sydeman, and S. D. Emslie. 1997. Cost of reproduction and the evolution of deferred breeding in the western gull. Behavioral Ecology 8:140-147.

Pyle, P., L. B. Spear, W. J. Sydeman, and D. G. Ainley. 1991. The effects of experience and age on the breeding performance of Western Gulls. Auk 108:25-33.

Reznick, D. 1985. Costs of reproduction: an evaluation of the empirical evidence. Oikos 44:257-267.

Ricklefs, R. E. 1974. Energetics of reproduction in birds. Pages 152-297 in R. A. Paynter, editor. Avian energetics. Publication of the Nuttall Ornithological Club Number 15. Cambridge, Massachusetls, USA.

Schmitz, R. A., and G. A. Baldassare. 1992. Contest asymmetry and multiple bird conflicts during foraging among nonbreeding American Flamingos in Yucatan, Mexico. Condor 94:254-259.

Searcy, W. A., and K. Yasukawa. 1981. Sexual size dimorphism and survival of male and female blackbirds (Icteridae). Auk 98:457-465.

Trivers, R. L. 1972. Parental investment and sexual selection. Pages 136-179 in B. Campbell, editor. Sexual selection and the descent of man, 1871-1971 Aldine, Chicago, Illinois, USA.

van Noordwijk, A. J., J. H. van Balen, and W. Scharloo. 1981. Genetic and environmental variation in clutch size of the great tit. Netherland Journal of Zoology 31:342-372.

Viallefont, A., E. G. Cooch, and F. Cooke. 1995. Estimation of trade-offs with capture-recapture models: a case study on the lesser snow goose. Journal of Applied Statistics 22: 847-861.

Ward, P. 1965. Seasonal changes in the sex ratio of Quelea quelea (Ploceidae). Ibis 107:397-399.

Weimerskirch, H. 1992. Reproductive effort in long-lived 
birds: age-specific patterns of condition, reproduction and survival in the wandering albatross. Oikos 64:464-473.

Williams, G. C. 1966. Natural selection, the cost of reproduction, and a refinement of Lack's principle. American Naturalist 100:687-690.
Wooller, R. D., J. S. Bradley, and J. P. Croxall. 1992. Longterm population studies of seabirds. Trends in Ecology and Evolution 7:111-114

Yom-Tov, Y., and J. G. Ollason. 1976. Sexual dimorphism and sex ratios in wild birds. Oikos 27:81-85.

\section{APPENDIX}

The following table provides explication of some models.

\begin{tabular}{ll}
\hline \hline \multicolumn{1}{c}{ Model notation } & \multicolumn{1}{c}{ Meaning } \\
\hline$t+A^{2}+s$ & Logit $(\phi)=\alpha_{0}+\alpha_{1} A+\alpha_{2} A^{2}+\alpha_{3} s+\beta_{t}$ \\
$w+\ln A+s$ & $\operatorname{Logit}(\phi)=\alpha_{0}+\alpha_{1} \ln A+\alpha_{2} s+\alpha_{3} w$ \\
$w+\ln A+s+s \ln A$ & $\operatorname{Logit}(\phi)=\alpha_{0}+\alpha_{1} \ln A+\alpha_{2} s+\alpha_{3} w+\alpha_{4} \sin A$ \\
\hline
\end{tabular}

Notes: $\operatorname{Logit}(x)=\log (x /(1-x)) ; A$ is true age; $w=1$ for $1984-1985$ and 0 for all other years; $s=0$ for males, 1 for females; $\alpha_{i}$ and $\beta_{t}$ are unknown constants to be estimated, and $\beta_{t}$ takes a different value for each time step $t$. 